D.-G. YU, B.-J. LI, S.-F. ZHENG, B.-T. GUAN, B.-Q. WANG, Z.-J. SHI* (PEKING

\title{
Nickel-Catalyzed Cross-Coupling of Aryl Grignard Reagents to Phenolate Salts
}

cross-coupling

aryl Grignard reagents

nickel<smiles>COc1ccc2ccccc2c1</smiles>

Met $=\mathrm{Li}, \mathrm{Na}, \mathrm{K}, \mathrm{MgX}$ $\mathrm{X}=\mathrm{Cl}, \mathrm{Br}, \mathrm{I}$
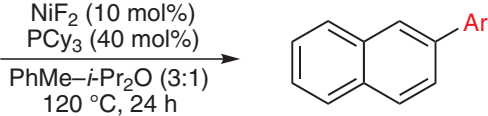

up to $92 \%$ yield

Selected examples:<smiles>C1=CC=Cc2cc(cc3ccccc23)C=C1</smiles>

$89 \%$ yield<smiles>Cc1cccc(-c2ccc3ccccc3c2)c1</smiles>

$86 \%$ yield<smiles>c1ccc2cc(-c3ccc(Cn4cccc4)cc3)ccc2c1</smiles>

$80 \%$ yield<smiles>c1ccc(-c2ccc3cc(-n4cccc4)ccc3c2)cc1</smiles>

$67 \%$ yield

Catalytic pathway:

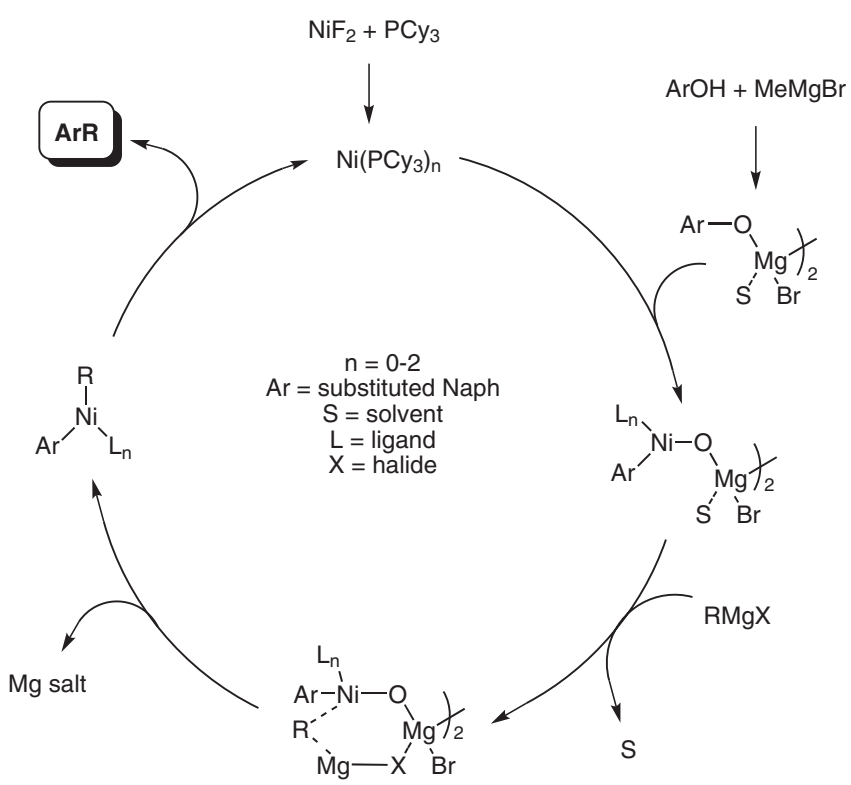

Significance: The first successful cross-coupling of 2-naphthol metal salts with various aryl Grignard reagents has been demonstrated. The process is atom-economical and gives a convenient access to various naphthalene derivatives.

SYNFACTS Contributors: Paul Knochel, Andreas J. Wagner Synfacts 2010, 9, 1051-1051 Published online: 23.08.2010 DoI: 10.1055/s-0030-1257897; Reg-No.: P09710SF
Comment: It is important to note that the halide substituent on the Grignard reagent is critical to the reaction and a bromide was found to be the best. The most efficient solvent system is a mixture of toluene and diisopropyl ether (3:1), most likely because these solvents retain the metallic core framework due to their low coordinating ability. 